\title{
Vitenskapelig uredelighet - kunnskap, handlinger og holdninger hos doktorgradskandidater
}

\begin{abstract}
BAKGRUNN Vitenskapelig uredelighet får stadig mer oppmerksomhet i fagtidsskrifter og i mediene, men vi vet forholdsvis lite om omfanget av fenomenet og holdninger til det eller hvordan dette endrer seg. Hensikten med studien var derfor å undersøke doktorgradskandidaters kunnskap om emnet, deres egne handlinger og deres holdninger til konkrete former for vitenskapelig uredelighet.
\end{abstract}

MATERIALE OG METODE Høsten 2015 ble det gjort en anonym spørreundersøkelse hos dem som deltok på introduksjonskurs for ph.d.-kandidater ved Det medisinske fakultet ved Universitetet i Oslo.

RESULTATER 77 ph.d.-kandidater (79\%) besvarte spørreskjemaet. $62 \%$ drev med klinisk forskning og $25 \%$ drev basalforskning. Rundt én av fire hadde hørt om alvorlige former for vitenskapelig uredelighet det siste året og rundt $4 \%$ var kjent med ulike former av dette fra egen avdeling i samme periode. Sammenlignet med tidligere studier svarte et økende antall (16\%) at de hadde vært utsatt for uetisk press når det gjelder inklusjon eller rekkefølge ved forfatterskap. Rundt to tredeler var usikre på om deres avdeling hadde retningslinjer for vitenskapelig atferd. En tredel av ph.d.-kandidatene tok ikke avstand fra handlinger som generelt oppfattes som vitenskapelig uredelige. En tidel mente det var akseptabelt å falsifisere eller fabrikkere data for å påskynde publisering, en femdel tok ikke avstand fra det å ta æren for andres ideer og nær halvparten mente at det ikke var galt å prøve ut en rekke analysemetoder til man får et signifikant svar.

FORTOLKNING Doktorgradskandidater ved Det medisinske fakultet kjente til forskningsfusk både generelt og fra egen avdeling. De rapporterte selv om noe forskningsfusk, og et stort flertall var usikre på avdelingens retningslinjer. Enkelte av kandidatene aksepterte også flere former for vitenskapelig uredelighet.

Vitenskapelig uredelighet er utpekt som et problem for forskningen - det er til hinder for vitenskapelige fremskritt, leder til misbruk av forskningsmidler, kan få følger for pasienter og folkehelse og undergraver tilliten til forskning generelt (1). Å definere og måle vitenskapelig uredelighet kan være vanskelig (2-4), og fordi fusk er vanskelig å avsløre, kan det være store mørketall.

Resultatene fra empiriske studier varierer (5-7). En kunnskapsoppsummering og metaanalyse fra 2009 viste at omtrent $2 \%$ av forskerne innrømmet å fabrikkert, falsifisert eller modifisert data en eller annen gang og at de var godt kjent med forskningsfusk gjort av kolleger (6). I nordisk og norsk sammenheng satte Sudbø-saken vitenskapelig uredelighet på agendaen. Noe kunnskap om ulike former for vitenskapelig uredelighet $\mathrm{i}$ de nordiske land har vi $(5,8-11)$, men kunnskapsgrunnlaget er fortsatt begrenset.

For å vurdere omfanget av vitenskapelig uredelighet slik at vi kan velge egnede virkemidler for å forebygge fremtidig forskningsfusk, har vi foretatt flere studier av doktorkandidaters kunnskap om temaet, deres handlinger og deres holdninger til vitenska- pelig uredelighet. I 2010/11 gjennomførte vi en studie ved alle de medisinske fakultetene i Norge. Den viste at det var betydelige forskjeller mellom studiestedene når det gjaldt kunnskaper og holdninger (11).

I 2014 gjennomførte vi en tilsvarende studie ved Universitetet i Oslo og Karolinska institutet i Stockholm (10). Også her så vi betydelige forskjeller i kunnskaper og holdninger mellom institusjonene. Universitetet i Oslo kom bedre ut enn Karolinska institutet på flere områder, samtidig som vi så at det var en uheldig utvikling i Oslo. Eksempelvis steg andelen doktorgradskandidater ved Universitetet i Oslo som følte seg presset når det gjaldt medforfatterskap og forfatterrekkefølge.

I løpet av de årene denne forskningen har pågått, har den fått oppmerksomhet både $\mathrm{i}$ Norge og internasjonalt så vel i forskningsmiljøene som i undervisningen. Vi ønsket derfor å undersøke hvordan doktorgradskandidaters kunnskap om vitenskapelig uredelighet, deres egne handlinger og deres holdninger til konkrete former for forskningsfusk har endret seg ved Universitetet i Oslo over tid. Slik kunnskap er viktig for å øke kunn-

\section{Bjørn Hofmann}

bjoern.hofmann@ntnu.no

Norges teknisk-naturvitenskapelige

universitet Gjøvik

og

Senter for medisinsk etikk

Universitetet i Oslo

\section{Søren Holm}

University of Manchester

og

Senter for medisinsk etikk

Universitetet i Oslo

> Se lederartikkel på side 1420

\section{HOVEDBUDSKAP}

Doktorgradskandidater ved Det medisinske fakultet ved Universitetet i Oslo kjenner til forskningsfusk både generelt og fra egen avdeling

Et stort flertall er usikre på sin egen avdelings retningslinjer for vitenskapelig redelighet

Noen av respondentene svarte positivt på at de selv har utført/begått vitenskapelig uredelighet

Antall kandidater som opplever uetisk press når det gjelder inklusjon eller rekkefølge ved forfatterskap er høyt og ser ut til å øke 
Tabell 1 Oversikt over antall spørreskjemaer distribuert og returnert sammen med svar om bakgrunn til respondentene

\begin{tabular}{|c|c|c|c|c|c|}
\hline Spørsmål/bakgrunnsinformasjon & Oslo 2015 & Oslo $2014^{1}$ & Oslo $2010^{2}$ & $\begin{array}{l}\text { Hele Norge } \\
\quad 2010^{2}\end{array}$ & $\begin{array}{l}\text { Hele Sverige } \\
2008 / 09^{3}\end{array}$ \\
\hline Returnert/distribuert (n) & $77 / 98$ & $96 / 107^{4}$ & $78 / 87$ & $189 / 262$ & $134 / 230$ \\
\hline Svarprosent (\%) & 78,6 & 88,8 & 89,7 & 72,1 & 58,3 \\
\hline Har tatt grunnutdanningen i Norge, antall (\%) & $37(48)$ & 55 (59) & $56(69)$ & $137(72)$ & - \\
\hline Forskning: Klinisk/basal/annen (n) & $45 / 18 / 10$ & $55 / 28 / 11$ & $31 / 30 / 16$ & $85 / 54 / 48$ & - \\
\hline Forskererfaring: < 1 år/1-2 år/> $2 \mathrm{ar}$ & $57 / 13 / 4$ & $75 / 17 / 3$ & $51 / 17 / 10$ & $118 / 50 / 21$ & - \\
\hline $\begin{array}{l}\text { Har hatt forelesninger eller kurs i vitenskapsetikk tidligere } \\
\text { (ja/nei/husker ikke) }\end{array}$ & $53 / 18 / 4$ & $71 / 15 / 8$ & $56 / 35 / 7$ & $124 / 66 / 20$ & - \\
\hline
\end{tabular}

Data for Oslo fra 2014 stammer fra Hofmann og medarbeidere (10)

2 Data for Norge fra 2010/11 stammer fra Hofmann og medarbeidere (11)

${ }^{3}$ Data for Sverige fra 2008/09 stammer fra Nilstun og medarbeidere (9)

${ }^{4}$ En besvarelse ble returnert helt blank log er ikke inkludert i beregningen av svarprosent. Hvis inkludert, ville svarprosenten være 80,0)

skapen, fremme gode holdninger og forebygge vitenskapelig uredelighet. I tillegg er det viktig å undersøke flere kohorter av doktorgradskandidater for å imøtegå en mulig innvending om at det er tilfeldig at noen $\mathrm{i}$ enkelte kohorter oppgir å ha vært utsatt for eller selv har medvirket til forskningsfusk. En undersøkelse av flere kohorter kan underbygge at de problemene som vi har funnet, forekommer konsistent over tid og ikke er et tilfeldig funn i én enkelt undersøkelse.

\section{Materiale og metode}

Et spørreskjema ble delt ut til alle deltagere ved et introduksjonskurs for alle doktorgradskandidater ved Det medisinske fakultet ved Universitetet i Oslo høsten 2015. Den første delen av skjemaet er utviklet i Lund i Sverige (9), den andre delen i USA (12). Skjemaet er tidligere brukt både i Norge og i Sverige $(10,11)$.

Svarkategorier var ja/nei/usikker for faktaspørsmål. Det ble brukt en Likert-type skala for spørsmål om holdninger (sterkt uenig/ uenig/verken enig eller uenig/enig/sterkt enig). Det var også mulighet for kommentarer i fritekst. Tabell 1 gir en oversikt over antall spørreskjemaer som ble distribuert og returnert og respondentenes bakgrunn. Enkelte av besvarelsene var ufullstendige, slik det fremgår av tallene i tabellen.

Statistikkanalysene er gjort i IBM SPSS Statistics versjon 22. Utvalget ble beskrevet med deskriptive analyser. Vi kontrollerte for om det var forskjell i svarene avhengig av hvor kandidatene har grunnutdanningen fra (i eller utenfor Norge), hvor ferske de var som forskere, hvorvidt de har hatt kurs $i$ vitenskapsetikk tidligere og hva slags type forskning de driver (grunnforskning eller klinisk forskning). Til dette er det brukt ordinære khikvadrattester og khikvadrattester for trend, med signifikansnivå $1 \%$. Dette signifikansnivået er valgt for å redusere faren for type 1-feil, da det ble gjort forholdsvis mange statistiske tester i dette materialet.

\section{Resultater}

Tabell 2 viser hvilken kjennskap kandidatene hadde til vitenskapelig uredelighet internasjonalt og ved egen avdeling. Tabellen viser også hva de selv rapporterte å ha gjort, hvorvidt de var blitt utsatt for uetisk press for å begå forskningsfusk samt om de hadde erfart konsekvenser av slikt - alt sammenlignet med resultater fra andre studier (9-11). Vi ser at kunnskapen om ulike former for vitenskapelig uredelighet, kjennskap til slikt ved egen avdeling og uetisk press når det gjelder inklusjon eller rekkefølge ved forfatterskap økte noe fra 2010 til 2015.

Av tabell 3 fremgår det hvor mange prosent av kandidatene som var usikre på om deres avdeling hadde skriftlige retningslinjer for flere konkrete forhold. Tabellen viser at andelen av kandidater som var usikre på avdelingens retningslinjer økte tallene for Universitetet i Oslo i 2015 er høyere enn gjennomsnittet for Norge i 2010 og Sverige i 2008/09.

Kandidatenes holdninger til ulike former for vitenskapelig uredelighet fremkommer av tabell $4.34 \%$ av respondentene mente at en eller flere handlinger som i litteraturen oppfattes som vitenskapelig uredelige, ikke var det - det vil si de åtte første spørsmålene i tabell 4: endre, falsifisere eller fabrikkere data, ta æren for andres arbeid eller gjenta analyser til man får statistisk signifikante resultater. Samtidig var det stor vilje til å rapportere vitenskapelig uredelighet hos andre.

Det var litt større villighet til å endre eksperimentelle data for å få et eksperiment til å se bedre ut enn det faktisk var og økende villighet til å melde fra om forskningsfusk i 2015 sammenlignet med det man har funnet i tidligere studier. Samtidig er det en nedgang i hvor villige kandidatene var til å ta æren for andres arbeid i tale, tekst eller som ideer og til å endre resultater (utelate, falsifisere eller fabrikkere) for å påskynde publisering.

I fritekstfeltet beskrev flere kandidater handlinger de selv hadde begått og som de oppfattet som tvilsomme. Ett eksempel var en kandidat som hadde utelatt svar fra en undersøkelse fordi disse kunne virke stigmatiserende på gruppen som ble studert. En annen hadde tolket kvalitative data slik at de passet best med budskapet. Kandidatene beskrev også forhold ved egen avdeling som de mente var tvilsomme, eksempelvis publisering av slurv, unøyaktigheter i presentasjoner og forskningssøknader og mistolking av forskningslitteratur.

Resultatene viser også at de som hadde deltatt på kurs i forskningsetikk tidligere, var mer enige $i$ at det aldri er riktig å ta æren for andres ideer enn de som ikke hadde slike kurs, at de som hadde studert utenfor Norge, hadde statistisk signifikant mer kjennskap til falsifiserte data enn de som hadde studert her $i$ landet og at de som drev med grunnforskning, hadde følt større press enn de andre til å presentere resultater på villedende måter.

\section{Diskusjon}

Resultatene viser at doktorgradskandidatene hadde kjennskap til vitenskapelig uredelighet både fra litteraturen, mediene og egen avdeling. Én person rapporterte å ha plagiert publikasjoner og to rapporterte at de hadde presentert resultater på en misvisende måte det siste året. En av ti rapporterte at noen ved 
Tabell 2 Svar på spørsmål om vitenskapelig uredelighet og annen uetisk oppførsel i forbindelse med forskning (de som har svart ja i prosent) ved det Medisinske fakultet ved Universitetet i Oslo 2015 sammenlignet med resultater for samme fakultet for 2010 og 2014 samt for alle medisinske fakulteter i hele Norge fra 2010 og tilsvarende fra Sverige fra 2008/09

\section{Spørsmål}

\section{Oslo 2015}

78,6
Oslo $2014^{1}$

90,5

\section{Oslo $2010^{2}$}

90,0

\section{Hele Norge} $2010^{2}$

72,1

29,2

$\begin{array}{rr}29,7 & 25,3 \\ 27,04,5 & 22,3 \\ 21,6 & 18,3 \\ 24,7 & 18,9\end{array}$

Plagiert publikasjoner
Hele Sverige $2008 / 09^{3}$

58

Har du selv i løpet av de siste 12 måneder vært utsatt for press til å

\begin{tabular}{|c|c|c|c|}
\hline Fabrikkere data & 0 & 0 & 1,3 \\
\hline Falsifisere data & 0 & 0 & 1,3 \\
\hline Plagiere data & 0 & 0 & 1,3 \\
\hline Plagiere publikasjoner & 0 & 0 & 0 \\
\hline Presentere resultater på noen annen misledende måte & $2,75,6$ & 0 & 1,3 \\
\hline
\end{tabular}

Har du selv i løpet av de siste 12 måneder

Fabrikkert data 0

Falsifisert data

$\begin{array}{lll}0 & 1,1 \\ 0 & 0\end{array}$

Plagiert data

Plagiert publikasjoner

Presentert resultater på noen annen misledende måte

Kjenner du noen ved din avdeling som i løpet av de siste 12 måneder har
Fabrikkert data
2,7
Falsifisert data
1,4
Plagiert (på noen måte)
10,0
Presentert resultater på noen annen misledende måte

4,3

$\begin{array}{rr}0 & 0 \\ 1,1 & 0 \\ 0 & 0 \\ 0 & 0 \\ 1,1 & -\end{array}$

1,5

1,5

Har du i løpet av de siste 12 måneder blitt utsatt for uetisk press med hensyn på

\begin{tabular}{|c|c|c|c|c|}
\hline Inklusjon eller rekkefølge ved forfatterskap & 16,0 & 12,8 & 10,4 & 10,6 \\
\hline Design/metode & 1,3 & 0 & 3,9 & 2,7 \\
\hline Analyse & $2,7^{5}$ & 2,1 & - & - \\
\hline Resultater & $1,3^{5}$ & 0 & 5,2 & 2,7 \\
\hline
\end{tabular}

Har du i løpet av de siste 12 måneder blitt utsatt for konsekvensene av vitenskapelig uredelighet

\begin{tabular}{llllll} 
Etisk & 5,4 & 3,2 & 5,2 & 5,9 & 0 \\
Juridisk & 2,7 & 3,2 & 1,3 & 1,1 & 3,2 \\
Metodologisk & 4,1 & 2,1 & 2,6 & 3,9 & 3,2 \\
På annen måte & 2,8 & 3,2 & 3,9 & 0 \\
\hline
\end{tabular}

1 Data for Norge fra 2014 stammer fra Hofmann og medarbeidere (10)

2 Data for Norge fra 2010/11 stammer fra Hofmann og medarbeidere (11)

${ }^{3}$ Data for Sverige fra 2008/09 stammer fra Nilstun og medarbeidere (9)

${ }^{4}$ Statistisk signifikant sammenheng med hvor de er utdannet (i versus utenfor Norge), khikvadrattest, signifikansnivå $1 \%$

${ }^{5}$ Statistisk signifikant sammenheng med hvor lenge de har forsket < 1 år, 1-2 år, $>2$ år), khikvadrattest for trend, signifikansnivå 1 \%

${ }^{6}$ Statistisk signifikant sammenheng med om kandidaten driver grunnforskning eller klinisk forskning, khikvadrattest, signifikansnivå $1 \%$ 
Tabell 3 Hvor mange ph.d.-kandidater var usikre om hvorvidt deres avdeling hadde skriftlige regler eller retningslinjer (i prosent)

\begin{tabular}{|c|c|c|c|c|c|}
\hline Spørsmål & Oslo 2015 & Oslo $2014^{1}$ & Oslo $2010^{2}$ & $\begin{array}{l}\text { Hele Norge } \\
2010^{2}\end{array}$ & $\begin{array}{l}\text { Hele Sverige } \\
2008 / 09^{3}\end{array}$ \\
\hline \multicolumn{6}{|c|}{ Har din avdeling skriftlige retningslinjer angående } \\
\hline Søknad om forskningsmidler & 64,8 & 60,6 & 46,2 & 54,0 & 59,2 \\
\hline Bruk av forskningsmidler & 67,1 & 59,6 & 38,5 & 52,9 & 57,7 \\
\hline Endringer av design/metode & $73,6^{4}$ & 66 & 62,8 & 68,3 & 47,3 \\
\hline Endringer av resultater & 77,1 & 66,7 & 64,1 & 69,4 & 43,1 \\
\hline Fabrikasjon av data & 63,9 & 63,4 & 42,3 & 57,5 & 44,6 \\
\hline Falsifikasjon av data & 63,9 & 62,4 & 42,3 & 57,5 & 43,8 \\
\hline Forfatterrekkefølge & 64,8 & 59,6 & 44,9 & 59,4 & 50,8 \\
\hline Plagiering av andre & 58,3 & 62,4 & 47,4 & 58,3 & 49,6 \\
\hline Dobbeltpublisering & 70,8 & 61,3 & 51,3 & 62,6 & 46,2 \\
\hline Trakassering & 64,8 & 68,8 & 48,7 & 62,6 & 43,8 \\
\hline
\end{tabular}

1 Data for Norge fra 2014 stammer fra Hofmann og medarbeidere (10)

2 Data for Norge fra 2010/11 stammer fra Hofmann og medarbeidere (11)

${ }^{3}$ Data for Sverige fra 2008/09 stammer fra Nilstun og medarbeidere (9)

${ }^{4}$ Statistisk signifikant sammenheng med hvor lenge de har forsket, $(<1$ år, 1-2 år, > år), khikvadrattest for trend, signifikansnivå 1 \%

deres avdeling hadde presentert resultater på en misvisende måte det siste året, og $16 \%$ var blitt utsatt for uetisk press om (med)forfatterskap. En tredel av respondentene mente at en eller flere handlinger som i litteraturen oppfattes vitenskapelig uredelige, ikke var det.

Disse resultatene stemmer godt overens med internasjonale (6) og nordiske (9-11, 13) studier. I vår studie var det mindre kjennskap til vitenskapelig uredelighet og færre rapporter om egen uredelighet enn i enkelte av studiene og også i en eldre norsk studie (14). Årsaken til dette kan være at vi har spurt om kunnskaper og handlinger $\mathrm{i}$ løpet av de siste 12 måneder, mens man i andre studier ikke har hatt denne presiseringen.

Enkelte av doktorgradskandidatene rapporterte om vitenskapelig uredelighet de selv hadde begått, selv om de fleste var ferske forskere. Slik uredelighet er problematisk selv om omfanget er lavt. Om den reelle forekomsten er større eller mindre enn det kandidatene rapporterer, er vanskelig å si, men det synes mer sannsynlig at respondentene vegrer seg for å rapportere om sin egen uredelighet enn at de overrapporterer.

$21 \%$ av respondentene hadde opplevd uetisk press $\mathrm{i}$ en eller annen form, hvorav $16 \%$ hadde vært utsatt for uetisk press om forfatterskap. Dette er mer enn tidligere (10, 11). Dessuten var $3 \%$ usikre på om de var blitt utsatt for uetisk press om forfatterskap. Det kan selvsagt være rimelig uenighet om forfatterskap og forfatterrekkefølge i mange sammenhenger og vi vet ikke noe om den konkrete situasjonen kandidatene har vært i, men ifølge svarene oppfattet de selv presset som uetisk.

Samlet sett hadde dessuten $15 \%$ av respondentene opplevd konsekvenser av vitenskapelig uredelighet $\mathrm{i}$ en eller annen form. Vi har ikke nærmere informasjon om hva dette gjelder, men det er mulig at enkelte har vært berørt av uredelighet oppdaget i større forskningsprosjekter som de er en del av.

Langt over halvparten av respondentene var usikre på om deres avdeling hadde retningslinjer for vitenskapelig uredelighet når det gjelder en rekke konkrete forskningsrelaterte aktiviteter. Andelen har økt sammenlignet med resultatet fra tidligere studier fra samme fakultet $(10,11)$. Det kan tyde på at informasjonen om eksisterende regelverk er blitt dårligere. Dette er urovekkende med tanke på forebygging av forskningsfusk.

Respondentenes holdninger til ulike former for vitenskapelig uredelighet gir også grunn til ettertanke. Selv om nivået ikke avviker vesentlig fra tidligere studier, kan man reflektere over at så mange som hver tiende doktorgradskandidat er villig til å falsifisere, fabrikkere eller utelate data dersom de er sikre på sine funn for å fremskynde publisering. Det er også bekymringsfullt at så mange som halvparten ikke finner det galt å prøve ut en rekke analysemetoder til de finner en som gir et statistisk signifikant resultat. Og sammenlignet med tidligere stu- dier er antallet som ikke synes det er galt å ta æren for andres ideer økt.

Samtidig er viljen til å rapportere vitenskapelig uredelighet hos medarbeidere, fagfeller, forskningsledere og veiledere meget høy - og økende. Det kan virke paradoksalt at respondentene synes å akseptere ulike former for vitenskapelig uredelighet når det gjelder dem selv, samtidig som de er villige til å rapportere det hos andre. Det kan selvsagt være at de har høy terskel for hva de oppfatter som normbrudd, men er villige til å rapportere det som de oppfatter som brudd, men kan også skyldes såkalt moralsk dissonans (15).

På grunnlag av kunnskap fra internasjonale studier og egne erfaringer testet vi hypoteser for konkrete sammenhenger. Én hypotese var at det (ikke) er noen sammenheng mellom tidligere deltagelse på kurs i forskningsetikk og kjennskap til, handlinger og holdninger til ulike former for vitenskapelig uredelighet. Her fant vi at de som tidligere hadde deltatt på slike kurs, var mer enige $i$ at det aldri er riktig å ta æren for andres ideer enn de som ikke hadde deltatt. Ut fra dette kan man neppe konkludere med at kurs i forskningsetikk har effekt $(16,17)$.

Tilsvarende testet vi hypoteser om sammenhengen mellom type forskning respondenten driver, hvor lenge vedkommende har forsket og kjennskap til, handlinger og holdninger overfor ulike former for vitenskapelig uredelighet. Mange av disse sammenhengene (tab 2, tab 3) kan forklares med at de 
Tabell 4 Andel av respondentene som svarte at de var enige eller sterkt enige i påstander om handlinger innen forskning (i prosent)

\begin{tabular}{|c|c|c|c|c|}
\hline Spørsmål & Oslo 2015 & Oslo $2014^{1}$ & Oslo $2010^{2}$ & $\begin{array}{l}\text { Hele Norge } \\
2010^{2}\end{array}$ \\
\hline $\begin{array}{l}\text { Det er aldri riktig å rapportere eksperimentelle data som er blitt generert uten å ha } \\
\text { gjennomført eksperimentet }\end{array}$ & 85,9 & 92,5 & 88,0 & 90,3 \\
\hline $\begin{array}{l}\text { Det er aldri riktig å endre eksperimentelle data for å få et eksperiment til å se bedre ut } \\
\text { enn det faktisk var }\end{array}$ & 97,3 & 98,9 & 92,2 & 96,3 \\
\hline $\begin{array}{l}\text { Det er aldri riktig å prøve en rekke analysemetoder til man finner en som gir et } \\
\text { statistisk signifikant resultat }\end{array}$ & 52,1 & 67,7 & 49,4 & 62,0 \\
\hline Det er aldri riktig å ta æren for noen andres arbeid i tale eller tekst & 90,5 & 97,8 & 93,5 & 95,2 \\
\hline Det er aldri riktig å ta æren for data som andre har fremskaffet & 86,5 & 95,7 & 85,5 & 88,1 \\
\hline Det er aldri riktig å ta æren for ideer som kommer fra noen andre & $79,7^{3}$ & 94,6 & 89,3 & 91,8 \\
\hline $\begin{array}{l}\text { Hvis du er sikker på dine funn, er det akseptabelt å utelate motstridende enkeltresul- } \\
\text { tater for å påskynde publiseringen }\end{array}$ & 11,1 & 14,3 & 18,1 & 12,8 \\
\hline $\begin{array}{l}\text { Hvis du er sikker på dine funn, er det akseptabelt å falsifisere eller fabrikkere data } \\
\text { for å påskynde publiseringen }\end{array}$ & 9,5 & 7,7 & 13,2 & 10,3 \\
\hline $\begin{array}{l}\text { Det er viktigere å være sannferdig i å rapportere data i publikasjoner enn i forsknings- } \\
\text { søknader }\end{array}$ & 40,8 & 33,7 & 35,1 & 29,3 \\
\hline $\begin{array}{l}\text { Hvis du oppdager noen som begår vitenskapelig uredelighet, så har du en plikt til } \\
\text { å melde fra }\end{array}$ & 91,8 & 89,2 & 87,0 & 87,1 \\
\hline $\begin{array}{l}\text { Hvis du har oppdaget at en medarbeider eller fagfelle har begått vitenskapelig urede- } \\
\text { lighet, da er du villig til å rapportere om dette til en som er ansvarlig }\end{array}$ & 89.0 & 79,3 & 79,2 & 79,0 \\
\hline $\begin{array}{l}\text { Dersom du har oppdaget at en veileder eller forskningsleder har begått vitenskapelig } \\
\text { uredelighet, da er du villig til å rapportere om dette til en som er ansvarlig. }\end{array}$ & 80,8 & 77,4 & 77,3 & 74,5 \\
\hline $\begin{array}{l}\text { Dersom fabrikkerte data er oppdaget i en publisert artikkel, må alle medforfattere } \\
\text { ta like stor del av ansvaret }\end{array}$ & 45,2 & 47,3 & 37,7 & 45,7 \\
\hline $\begin{array}{l}\text { Dersom fabrikkerte data er oppdaget i en publisert artikkel, må alle medforfattere } \\
\text { ta like stor del av straffen }\end{array}$ & 26,8 & 34,4 & 24,7 & 28,8 \\
\hline
\end{tabular}

1 Data for Oslo fra 2014 stammer fra Hofmann og medarbeidere (10)

2 Data for Norge fra 2010 stammer fra Hofmann og medarbeidere (11)

${ }^{3}$ Statistisk signifikant sammenheng med om kandidaten har kurs i vitenskapsetikk fra tidligere, khikvadrattest, signifikansnivå $1 \%$

har kommet lenger i forskningsprosessen (og dermed har større mulighet til å oppleve press, eksempelvis om analyse og publisering). Vi ville trolig ha funnet langt flere sammenhenger om vi ikke hadde vært så strenge i signifikanstestene, men siden tallene er så vidt små, har vi vært forsiktige med å tolke slike sammenhenger.

Som med alle spørreundersøkelser er det en rekke metodiske utfordringer med denne studien. Disse har vi gjort nærmere rede for tidligere $(10,11)$. Ett viktig spørsmål er hvorvidt respondentene har oppfattet spørsmålene likt og riktig. «Å ta æren for» og «riktig» kan utvilsomt tolkes ulikt. I en spørreundersøkelse om vitenskapelig uredelighet vil det likevel være grunn til å tro at slike termer tolkes opp mot vitenskapsetiske normer. En annen utfordring er at spørreskjemaet ikke er validert.
Vår studie tyder på at doktorgradskandidater ved Det medisinske fakultet ved Universitetet i Oslo kjenner til forskningsfusk både generelt og fra egen avdeling. Enkelte oppgir at de det siste året har begått vitenskapelig uredelighet. Hver femte doktorgradskandidat hadde vært utsatt for uetisk press, de fleste om forfatterskap. Et flertall var usikre på om deres avdeling hadde regler for vitenskapelig redelighet, og en betydelig andel av kandidatene aksepterer handlinger som oppfattes som uredelige.

Vi takker respondentene for at de har vært villige til å delta i denne studien, Jan Helge Solbakk for hjelp med å distribuere og samle inn spørreskjemaene ved det første av to kurs og Magne Thoresen for kritisk og god hjelp med de statistiske analysene.

\section{Bjørn Hofmann (f. 1964)}

er professor i medisinsk filosofi og etikk ved Norges teknisk-naturvitenskapelige universitet på Gjøvik og ved Universitetet i Oslo. Han forsker og underviser innenfor medisinsk filosofi, etikk, og vitenskapsteori.

Forfatter har fylt ut ICMJE-skjemaet og oppgir ingen interessekonflikter.

\section{Søren Holm (f. 1963)}

er professor i medisinsk etikk ved Centre for Social Ethics and Policy, ved School of Law ved University of Manchester og ved Senter for medisinsk etikk ved Universitetet i Oslo. Han har hatt en rekke prestisjefylte verv, blant annet president i International association for bioethics (IAB). Forfatter har fylt ut ICMJE-skjemaet og oppgir ingen interessekonflikter. 


\section{Litteratur}

1. Michalek AM, Hutson AD, Wicher CP et al. The costs and underappreciated consequences of research misconduct: a case study. PLoS Med 2010; 7: e1000318

2. White C. Suspected research fraud: difficulties of getting at the truth. BMJ 2005; 331: $281-8$.

3. Fanelli D, loannidis JP. US studies may overestimate effect sizes in softer research. Proc Nat Acad Sci U S A 2013; 110: 15031-6. . (PNAS).

4. Fanelli D. The black, the white and the grey areas: Towards an international and interdisciplinary definition of scientific misconduct. I: Mayer T. Stencke N, red. Promoting research integrity in a global environment. Singapore: World Scientific Publishing, 2011: 79-90.

5. Nylenna M, Fagerbakk F, Kierulf P. Authorship: attitudes and practice among Norwegian researchers. BMC Med Ethics 2014; 15: 53.

6. Fanelli D. How many scientists fabricate and falsify research? A systematic review and meta-analysis of survey data. PLoS One 2009; 4: e5738.

7. Roberts DL, St John FA. Estimating the prevalence of researcher misconduct: a study of UK academics within biological sciences. PeerJ 2014; 2: e562.

8. Nylenna M, Andersen D. Dahlquist $G$ et al. Handling of scientific dishonesty in the Nordic countries. Lancet 1999; 354: 57-61

9. Nilstun T, Löfmark R, Lundqvist A. Scientific dishonesty-questionnaire to doctoral students in Sweden. J Med Ethics 2010; 36: 315-8.

10. Hofmann B, Helgesson G, Juth N et al. Scientific Dishonesty: A Survey of Doctoral Students at the Major Medical Faculties in Sweden and Norway. J Empir Res Hum Res Ethics 2015; 10: 380-8.

11. Hofmann B, Myhr Al, Holm S. Scientific dishonesty - a nationwide survey of doctoral students in Norway. BMC Med Ethics 2013; 14: 3

12. Kalichman MW. Friedman PJ. A pilot study of biomedical trainees' perceptions concerning research ethics. Acad Med 1992; 67: 769-75

13. Elgesem D, Jåsund K, Kaiser M. Fusk i forskningen. En studie av uredelighet og diskutable forskning ved norske universiteter. Oslo: Universitetet i Oslo, 1997

14. Bekkelund SI, Hegstad AC, Førde OH. Uredelighet i medisinsk og helsefaglig forskning i Norge. Tidsskr Nor Lægeforen 1995: 115: 3148-51.

15. Anderson MS, Martinson BC, De Vries R. Normative dissonance in science: results from a national survey of u.s. Scientists. J Empir Res Hum Res Ethics 2007; 2: 3-14.

16. Anderson MS, Horn AS, Risbey KR et al. What do mentoring and training in the responsible conduct of research have to do with scientists' misbehavior? Findings from a National Survey of $\mathrm{NIH}$-funded scientists. Acad Med 2007; 82: 853-60.

17. Marusic A, Wager E, Utrobicic A et al. Interventions to prevent misconduct and promote integrity in research and publication. Cochrane Database Syst Rev 2016; 4: MR000038.

Mottatt 22.2. 2016, første revisjon innsendt 9.5. 2016, godkjent 21.6. 2016. Redaktør: Geir Wenberg Jacobsen. 